13. Rautava J. F. The Role of Oil Prices and the Real Exchange Rate on Russia's Economy. BOFIT Discussion Papers. 2002. No. 24. pp. 41-65.

14. Chuku C. A., Effiong E. J., Sam N. K. Oil price distortions and their short- and long-run impacts on the Nigerian economy. 2010. Available at: http://mpra.ub.uni-muenchen.de/24434/ (accessed: 24.06.2019)

15. Sachs J. D., Warner A. M. The Curse of Natural Resources. European Economic Review. 2001. Vol. 45. pp. 827-838.

16. Gylfason T. A. Natural Resources, Education, and Economic Development. European Economic Review. 2001. Vol. 45. pp. 847-859.

17. Alexeev M. V., Conrad R. J. The Elusive Curse of Oil. SAN Working Paper. 2005. No 7. pp. 201-229.

18. Stijns J.-P. C. Natural Resource Abundance and Economic Growth Revisited. Resources Policy. 2005. Vol. 30(2). pp. 107-130.

19. Brunnschweiler C. N. Cursing the Blessings? Natural Resource Abundance, Institutions, and Economic Growth. ETH Economics Working Paper. 2006. Vol. 51. pp. 83-101.

20. Polterovich V., Popov V., Tonis A. Mechanisms of the «resource curse» and economic policy. Voprosy Ekonomiki. 2007. No. 6. pp. 4-27.

21. Kontorovich A. E., Eder L. V., Filimonova I. V., Nikitenko S. M. Key Problems in the Development of the Power of Siberia
Project. Regional Research of Russia. 2018. Vol. 8, No. 1 pp. 92-100. DOI: 10.1134/S2079970518010057

22. Nikitenko S. M., Goosen E. V., Kontorovich A. E. Shift of the world energy sector development paradigm: Consequences for Russia. IOP Conference Series: Earth and Environmental Science. 2018. Vol. 206, No 1. pp. 120-153. DOI: 10.1088/1755$1315 / 206 / 1 / 012053$

23. Eder L. V., Komarova A. V., Filimonova I. V. et al. Sustainable development of resource regions on the declining stage of production: Innovative technologies and economic efficiency. IOP Conference Series: Earth and Environmental Science. 2018. Vol. 206, No. 1. pp. 110-119 DOI: 10.1088/1755-1315/206/1/012056

24. Eder L. V., Provornaya I. V., Filimonova I. V. Problems of Rational Use of Associated Petroleum Gas in Russia. Geography and Natural Resources. 2019. Vol. 40, No. 1. pp. 9-14. DOI: $10.1134 / \mathrm{S} 1875372819010025$

25. Filimonova I. V., Eder L. V., Komarova A. V., Provornaya I. V., Nemov V. Y. Resource regions of Russia: Socio-economic indicators and innovative development. IOP Conference Series: Earth and Environmental Science. 2018. Vol. 206, No. 1 pp. 97-104. DOI: 10.1088/1755-1315/206/1/012020

26. Kontorovich A. E., Eder L. V., Filimonova I. V., Mishenin M. V. The role of unique and large deposits in Russian oil sector: retrospective analysis, current state and forecast. Energeticheskaya politika. 2016. No. 2. pp. 34-43.

UDC 330.15

A. V. DUSHIN ${ }^{1}$, Rector, Doctor of Economic Sciences

M. N. IGNATYEVA ${ }^{1,2}$, Doctor of Economic Sciences, rinis@mail.ru

V. V. YURAK ${ }^{1,2}$, Associate Professor, Candidate of Economic Sciences

A. N. IVANOV ${ }^{1}$, Senior Lecturer

1 Ural state mining university, The Ural Branch of Russian Academy of Sciences, Yekaterinburg, Russia

2 Institute of Economics, The Ural Branch of Russian Academy of Sciences, Yekaterinburg, Russia

\title{
ECONOMIC EVALUATION OF ENVIRONMENTAL IMPACT OF MINING: ECOSYSTEM APPROACH
}

\section{Introduction}

Nowadays one of the main sources of environmental problems continues to be the mining sector, under the anthropogenic impact which hurts almost all elements of the biosphere. According to the authors' estimates [1], in the industry breakdown, the greatest damage of unit production is caused in the power industry and the coal industry. The proportion of damage caused by the production in mineral industries such as fuel, ferrous and nonferrous metallurgy is about $70 \%$ of the total damage impaired by pollution of the atmosphere and water bodies. Given the link between the level of economic advance, which is determined, first of all, by the development of the primary sector, and the degree of environmental pollution, we cannot expect improvement in the environmental situation, because mining today and in the foreseeable future is the unalienable necessity of mankind existence.

The Russian Strategy Concept of Socio-Economic Development until 2020 declares one of
The article considers the most important aspects of ecosystem approach implementation in mining. It requires the integrated economic assessment of the environmental consequences and the entire list of ecosystem services supplied by forest ecosystems most subjected anthropogenic impact of mineral mining. The authors identify the main ecosystem services supplied by forests and indirectly providing economic benefits to their consumers: maintenance of air composition in the atmosphere (carbon sequestration and oxygen production); air purification and water protection associated with an increase in precipitation and soil protection from erosion. The scientific novelty consists in the improvement of guidelines for economic assessment of ecosystem services generated by natural capital of the territories under consideration. The guidelines are developed for assessing the ecosystem service on air composition maintenance at various degree of detalization. The introduction of the decrease in precipitation due to rainfall retention by forest canopy in the economic assessment of water protection service is substantiated. The article systematizes approaches to economic assessment approaches of soil protection ecoservice, which allows selecting the most appropriate method for the specific conditions. The experience of using the discounting procedure in economic valuation of ecosystem services is summarized and analyzed.

Key words: mining, impact, consequences, economic assessment/evaluation, ecosystem services, economic damage.

DOI: $10.17580 /$ em.2020.01.06 
the Russian economy priorities to be the abandonment of the raw material development model and the need of transition to a "green economy". The most important specific characteristic of this priority is to prevent the threat to ecosystem services and biodiversity, to conserve the natural capital and to ensure human well-being and social justice. The plurality of the most urgent goals and indicators of the national project implementation in the field of ecology confirms the requirement of the ecosystem potential preservation. It is approved by Decree of the President of the Russian Federation, No. 204 as of 07.05.2018 (ed. of 07/19/2018) "On the national goals and strategic objectives of the Russian Federation development for the period up to 2024", which is focused on reducing the anthropogenic environmental load and expanding areas with natural ecosystems. Under these conditions in order to prevent or mitigate adverse anthropogenic impacts, environmental impact assessment with a full-fledged consequence analysis becomes particularly important. This assessment helps predict potential economic damage and make decisions that balance interaction in the society-nature system.

An important point in determining the economic damage is the economic assessment of natural resources and ecosystem services. Meanwhile the economic assessment of natural resources has been carried out for a long time, the guidelines for the economic assessment of ecosystem services are at the start point. As a result, only a small amount of ecosystem services becomes involved in the modern economic system, and most of them remain unvalued. At the same time, those not so numerous assessments of ecosystem capital show its significant superiority in value compared to natural resource capital, which actualizes the problem of economic valuation of ecosystem services.

\section{The current status of research}

Ecological and economic interactions with the assessment of ecosystem services and economic damage is the research field of many Russian and foreign scientists such as A. L. Bobrov, S. N. Bobylev, I. P. Glazyrina, A. A. Golub, A. A. Gusev, V. I. DanilovDanilyan, K. Ya. Kondratiev, K. S. Losev, N. N. Lukyanchikov, A. S. Martynov, O. E. Medvedeva, T. E. Mekush, G. A. Motkin, R. A. Perelet, I. M. Potravny, K. V. Papenov, E. V. Ryumina, A. A. Tishkov, A. G. Rosenberg, G. A. Fomenko, M. A. Fomenko, V. V. Yurak, E. B. Barbier, J. Bishop, R. H. Born, A. G. Bruner, H. E. Daly, J. Dixon, R. Costanza, S. Pagiola, D. W. Peare, P. Y. Ferraro, W. M. Hanemann and others.

With all the detailed development of theoretical and methodological foundations and a variety of methodological approaches to the economic valuation of ecosystem services, a number of issues of theory and practice remain yet little studied due to the novelty of the problem, the appearance of which dates back to the beginning of the 20th century. A preventive approach to the assessment of the damage from different mining scenarios helps prevent loss or reduction of ecosystem services to human well-being. A key step towards achieving a positive result is the development of reliable tools for the economic evaluation of the natural capital components.

\section{Purpose, objectives and scientific novelty of research}

The aim of the study is to improve the methodological tools for the economic assessment of environmental impacts caused by the anthropogenic environmental loads during mining.

The objectives of the study are: 1 ) to identify the most dangerous mining impacts and to form ecological zones; 2) to justify the possibility of using the resource approach to determining the economic damage; 3 ) to improve the guidelines for the economic assessment of the environmental impacts of mining.

The scientific novelty of the research lies in the development of the theoretical framework for the formation of natural capital and in the improvement of the guidelines for the economic evaluation of its components.

\section{Anthropogenic impact of mining industries on the environment with the formation of ecological zones}

Modern conditions are characterized by the aggravated contradictions in the society-nature system. The rise of the economic potential, that satisfies the needs of the growing population, is accompanied by ever-increasing destructive manmade pressure on natural systems. Improvement of economic indicators is going with the environmental degradation: depletion of fish resources, decrease in forest area, expansion of erosion, loss of pastures, growth of deserts, melting of glaciers, etc. According to V. A. Koptyug the implementation of social equality in the world requires raising income by almost 5 times to $80 \%$ of the population and increasing further production on the planet. This will cause the rising use of natural resources by almost 20 times [2], which will undoubtedly lead to ecological disaster [3]

Nowadays one of the main sources of environmental problems is the mining industry, which has the strongest influence on the atmosphere and land resources in case of the open method of mining and on the groundwater and lithosphere in underground method of mining. The effect on the atmosphere appears in the form of dustiness and gas pollution. The particular danger is dust containing toxic metals-lead, mercury, arsenic, manganese, zinc, etc.: it affects both plants and animals. Polluting gases mainly enter the atmosphere from underground mining. In particular, in coal mines, emissions contain sulfur gases, methane, carbon dioxide, hydrogen sulfide and other pollutants, which contributes to the greenhouse effect. Emissions of carbon dioxide and sulfur dioxide lead to acid rain, which, for example, in the countryside of Norilsk, led to destruction of forests in an area of more than 180 thousand hectares [4].

The consequences of the impact on water resources are no less destructive: changes in the water regime, water pollution. Mineral water may contain a set of salts of heavy metals: copper, zinc, manganese, mercury, lead, etc. The discharge of polluted wastewater into water bodies contributes to the accumulation of toxic substances in aquatic organisms, disease and death of the latter. Contamination of water bodies is the most sever at the points of polluted wastewater discharge. Lands suffer as well. The mineral mining governs withdrawal of considerable agricultural and forestry lands and their transition to the category of industrial areas. As a result, soil in the mineadjacent areas becomes unsuitable for the normal functioning of ecosystems; the earth's surface is disturbed and polluted. Waste containing toxic substances, which become a source of environmental pollution, is placed on ground surface. Waste occupies tens thousands hectares in old industrial regions and is often stored on the industrial infrastructure sites of underground mines or in abandoned quarries.

Ecological changes at the impact sources lead primarily to disturbances in the biocenosis as the most sensitive element of ecosystems. Accumulated pollutants in vegetation are considered as markers in territorial differentiation by the rate of anthropogenic pollution. The successive transformation of 
ecosystems is assessed as a phase of suppression of species, phase of loss of sensitive species, phase of structural rearrangements of ecosystems and, finally, a phase of destruction of ecosystems [5]. According to the research [6], the operation area of Severonikel is discriminated into zones of the initial disturbance of forest ecosystems, partial disturbance of forest ecosystems, strong disturbance and completely disturbed ecosystems. Numerous studies by the present authors confirm the formation of ecological zones around the impact sources with varying degrees of ecosystem disturbance. Depending on the impact and ecological sustainability of exposed ecosystems, the sizes of ecological zones vary but their pattern remains.

\section{Natural capital structure and resource approach to economic damage assessment}

While satisfying needs and wants, a human affects nature (natural capital), including mineral mining. By extracting mineral reserves, the mining industry depletes natural resources and leads to the degradation of ecosystems exposed to the adverse effects. Back in 1998, G. Daly defined natural capital as a stock of natural resources, which provides a flow goods and services. The latter definitions include the following: "natural capital is an economic model of organic reserves of physical and biological resources and the limited ability of ecosystems to provide ecosystem services" [7] or, as defined by authors [8], "Natural reserves that ensure the availability of natural resources and ecosystem services for economic production and human well-being".

The economic assessment of natural resources requires specification of the components of natural capital. We consider it is necessary to distinguish between two types of natural capital functions: resource and ecosystem (See figure).

The resource functions of natural capital satisfy the needs of a human (society) for the subjects of labor, instruments of labor, materials and consumer goods. The ecosystem functions are implemented as a flow of ecosystem services directly (social ecoservices) or indirectly (regulative ecoservices) are consumed by a human.

Forest ecosystems more often fall under the anthropogenic impact since mining is carried out in the forestry areas. The rate of disturbance varies in different ecological zones.

According to [9-12], the resource approach can be successfully used to assess economic damage determined by the loss of the economic value of a resource transformed under impact of mining initiated by a human:

$$
y_{i}=O_{i} \mathrm{a} \text {, }
$$

where $y_{i}$ is the economic damage due to decrease in the economic value of an $i$-th natural resource; $O_{i}$ is the ecological assessment index of the $i$-th natural resource; $a$ is the coefficient of reduction in economic value of the $i$-th natural resource.

Experience shows that the decrease in economic value is to some extent correlated with the damage rate of a natural resource. The methodological recommendations [5] propose to use a system of indicators characterizing the succession of ecological zones (Table 1).

As follows from the table, there are four ecological zones with tremendous, severe, moderate and weak damage of ecosystems. Disturbance increases with a decreasing distance to the source of anthropogenic impact. At the industrial infrastructure, the rate of damage is estimated by coefficient 1.0 , which means the biota is killed. When determining the rate of disturbance, it is indicated that at the first level of disturbance,

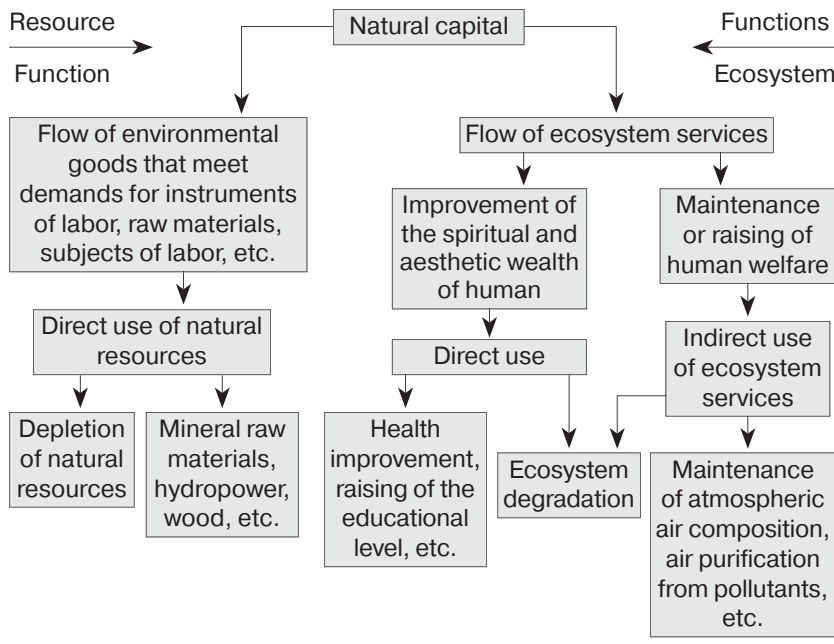

Natural capital structure

Table 1. Coefficient of reduction in economic value of natural resources [5]

\begin{tabular}{|c|c|c|c|c|}
\hline \multirow[b]{2}{*}{$\begin{array}{l}\text { Types of } \\
\text { resources }\end{array}$} & \multicolumn{4}{|c|}{ Rate of damage of ecosystem } \\
\hline & $\begin{array}{c}\text { Weak } \\
\text { (satisfactory) }\end{array}$ & $\begin{array}{c}\text { Moderate } \\
\text { (conditionally } \\
\text { satisfactory) }\end{array}$ & $\begin{array}{l}\text { Severe } \\
\text { (crisis) }\end{array}$ & $\begin{array}{l}\text { Tremendous } \\
\text { (catastrophic) }\end{array}$ \\
\hline $\begin{array}{l}\text { Forest, } \\
\text { wild-growing } \\
\text { herb, hunting } \\
\text { areas, land }\end{array}$ & $0.1-0.3$ & $0.31-0.65$ & $\begin{array}{c}0.66- \\
0.85\end{array}$ & $0.86-1.0$ \\
\hline
\end{tabular}

suppression of most species is observed but self-recoverability is preserved. At the second level, there is a decrease in the productivity and sustainability of flora and fauna, as well as an increase in the degree of their instability. The third level features significant losses in productivity and sustainability, and the fourth level of damage means the total loss of productivity and stability of plant and animal communities.

An important point in determining the economic damage in these conditions is the economic assessment of natural resources and ecosystem services. Methodical approaches to the economic assessment of natural resources supplied by forest ecosystems are described in sufficient detail in [13, 14]. This article focuses on the economic assessment of the most significant (according to the results of an expert survey) ecosystem services.

Ecosystem services are the benefits that humanity receives from ecosystems, including providing services (supply of food, water, forest, raw materials), or in the definition of the present authors-the economic benefits from implementation of resource functions, including regulating (climate regulation, water regulation, water purification, control over natural disasters, etc.), social (aesthetic, spiritual values, educational services, recreational resources) and supporting services (soil formation, nitrogen cycle, photosynthesis, etc.). The economic assessment of ecosystem services allows increasing validity of managerial decisions by economic damage amendment and comparison with the estimated economic effect of mineral mining.

\section{Economic assessments of environmental impacts of} mining as the basis for economic damage calculation

One of the most significant ecosystem services related to forest ecosystems is maintaining the air composition of the 
atmosphere. Until recently, it was believed that phytoplankton was the main absorber of $\mathrm{CO}_{2}$ from the atmosphere, but the recent studies show that the phytomass productivity is 2 times higher than phytoplankton has; it means that forest ecosystems are the main absorber of $\mathrm{CO}_{2}$. Carbon dioxide in the atmosphere or carbon dioxide dissolved in water and water ensure the formation of organic matter and the release of oxygen $\left(\mathrm{O}_{2}\right)$ during photosynthesis, while the oxidation and decomposition of organic matter consume $\mathrm{O}_{2}$ and produce $\mathrm{CO}_{2}$ and water. The calculation of the economic value of these ecosystem services (oxygen production and carbon sequestration) can be performed with varying degrees of detail. In the very first approximation, the economic assessment of $\mathrm{CO}_{2}$ sequestration and $\mathrm{O}_{2}$ production can be carried out on the basis of averaged plantings, the relevant increase in biomass and averaged values of $\mathrm{CO}_{2}$ sequestration -1.83 tons per ton of dry organic matter and $\mathrm{O}_{2}$ production -1.4 tons per ton of dry organic matter:

$$
\mathrm{O}_{\mathrm{CO}_{2}}^{\prime}=1.83 \mathrm{GCC}_{\mathrm{C}} \mathrm{P}_{\mathrm{CO}_{2}}
$$
where $\mathrm{O}_{\mathrm{CO}_{2}}$ is the economic value of ecosystem service on $\mathrm{CO}_{2}$ sequestration per hectare, rubles per ha; $G$ is the annual growth of vegetation, tons per ha; $\mathrm{CC}_{\mathrm{C}}$ is the coefficient of conversion of biomass into dry organic matter, decimal quantity (it is assumed that drying reduces weight of wood by $50 \%$ ); $\mathrm{P}_{\mathrm{CO}_{2}}$ is the price of 1 ton of $\mathrm{CO}_{2}$, rubles.

The economic assessment of a forestland $\left(\mathrm{O}_{\mathrm{CO}_{2}}\right)$ requires the information about the forested area:

$$
\mathrm{O}_{\mathrm{CO}_{2}}=\mathrm{O}_{\mathrm{CO}_{2}}^{\prime} \mathrm{S} \text {, }
$$

where $S$ is the forested area, ha.

Detailing involves taking into account the plantation types and the areas they occupy:

$$
\mathrm{O}_{\mathrm{CO}_{2}}=\sum_{j=1}^{\mathrm{m}} \mathrm{O}_{\mathrm{CO}_{2} j}^{\prime} S_{j}
$$

where $\mathrm{O}_{\mathrm{CO}_{2} j}$ is the economic value of ecosystem service for $\mathrm{CO}_{2}$ sequestration per 1 ha occupied by an $j$-th plantation type, rubles per ha; $S_{j}$ is the area occupied by the $j$-th plantation type, ha; $j$ is the plantation type $(j=1 \ldots \mathrm{m})$.

If the increment value is in cubic meters, then conversion to tons is performed using data on the density of wood in completely dry state, which is taken into account in tons per cubic meter. Thus, according to [14], the density of wood in the forests of the Middle Urals is $0.44-0.524$ for all types of forests, where 0.44 tons per cubic meter is the density of young forest, 0.477 for middle-aged and 0.524 for maturing forest. In the case of using density, the coefficient $\left(\mathrm{CC}_{\mathrm{C}}\right)$ in formula (2) is not taken into account. Calculation of oxygen production (ecosystem service) is carried out similarly, using information about $\mathrm{O}_{2}$ production by various types of vegetation and the price of 1 ton of $\mathrm{O}_{2}$.

The cost of 1 ton of $\mathrm{CO}_{2}$ can be taken according to the Kyoto Protocol from USD 10 to 50, on average USD 30, with regard to the rate of the Central Bank at the date of the calculations. In the capacity of cost, it is also possible to use the value of substitute expenses determined as the expenses connected with creation of $\mathrm{CO}_{2}$ emission prevention system. Regarding production of 1 ton of $\mathrm{O}_{2}$, the substitute expenses connected with industrial production of $\mathrm{O}_{2}$ are taken into account. Some researchers assume the cost of 1 tone of $\mathrm{O}_{2}$ as 2000-3000 rubles. The authors of [15] determine the substitute cost as 960-11000 rubles per ton depending on the process solution. According to [16] the cost of $\mathrm{O}_{2}$ is 8200 rubles per ton.

The similarly simplified guidelines to the economic evaluation of the ecosystem services are proposed in [17]:

$$
\mathrm{O}_{\mathrm{CO}_{2}}=0.5 \cdot 3.66 \sum_{j=1}^{\mathrm{m}} G_{1} C C_{C} S_{j} P_{\mathrm{CO}_{2}}
$$

where 0.5 is the ratio of carbon to the total dry phytomass of plants [18]; 3.66 is the $\mathrm{C}$ to $\mathrm{CO}_{2}$ conversion coefficient;

$$
\mathrm{O}_{\mathrm{O}_{2}}=0.5 \cdot 3.66 \cdot 0.727 \sum_{j=1}^{\mathrm{m}} \mathrm{G}_{1} C C_{C} S_{j} P_{\mathrm{CO}_{2}},
$$

where 0.727 is $\mathrm{O}_{2}$ produced in sequestration of 1 ton of $\mathrm{CO}_{2}$.

The next detailing step is to take into account the age of planting, the corresponding values of forest yield and the values of $\mathrm{CO}_{2}$ sequestration and $\mathrm{O}_{2}$ production, information about which is rather limited. As follows from [14], the greatest absorption of $\mathrm{CO}_{2}$ is primarily characteristic of young forest, the least $\mathrm{CO}_{2}$ is absorbed by mature and overmature forest. Refinement by the criterion of age group makes the economic value of ecosystem services often incomparable with the estimate based on averaged parameters, which is explained by the significant influence of the forest age on the forest yield. Further specification concerns the magnitude of gain in phytomass and associated carbon it in the framework of same-aged forest stands, which involves the conversion-volume method $[19,20]$ conditionally called group-age method. Conversion factors, which are the ratios of phytomass of different fractions to the stock of wood, are usually determined for the age groups of stands of individual forest-forming species, and make it possible to take into account the total gain in the whole phytomass of forest stands. The generalization and analysis of the available experience in economic assessment of ecosystem services for the $\mathrm{CO}_{2}$ sequestration and $\mathrm{O}_{2}$ production shows that the conversion-volume method is used very seldom, and there are no direct calculations to prove the actual application of the method. The economic assessment of the ecosystem service of air purification from dust by forest resources is recommended to do by using the cost approach. The expert survey shows that every 1 hectare of the northern forest can catch about 30 tons of dust [21]. Approximately the same range is indicated in $[22,23]$ : coniferous forests trap 30-40 tons of dust on crowns, oak dust-about 54 tons, beech forests-68 tons; in some cases the filtered mass of dust can reach 50-70 tons per year. For the conditions of the Middle Urals, dust capture by forest crown is estimated at an average of 50 tons per ha. In addition to dust, forests trap gaseous and aerosol pollutants.

$$
O_{o r}=\sum_{j=1}^{m} S_{j} D E_{\rho}
$$

where $O_{o r}$ is the economic value of air purification ecosystem service, rubles; $t_{\mathrm{oj}}$ is the dust trapping by a $\mathrm{j}$-th plantation type, tons per ha; $S_{j}$ is the area occupied by the $j$ - plantation type, ha; $D E_{p}$ - is the day-to-day expenditures on air purification from dust, rubles per ton.

Taking into account the most common air purification methods, the day-to-day or substitute cost make 1.2-3.5 thousand rubles per ton $[15,24]$, or $2.8-4.5$ thousand rubles per ton sometimes. The recommended value for the substitute costs is 3.5 thousand rubles per ton.

All researchers recognize the water protection role of forests, which results in the increase in precipitation, decrease in surface runoff, and in the soil protection from erosion.

First of all, precipitation in the forest-covered territory increases. Numerous researches prove the effect of forest on rainfall. On average, rainfall grows by $2 \%$ per each $10 \%$ of the forest-covered territory compared with the nonforest area 
[25]. V. V. Rakhmanov confirms this consistent pattern by the correlation equation. In the Middle Urals $1 \%$ growth in woodiness increases rainfall by $1.5 \mathrm{~mm}$ ( 15 cubic meters per year); $10 \%$ growth in woodiness increases rainfall by $8-12 \mathrm{~mm}$ in the European territory and by $12-13 \mathrm{~mm}$ in Siberia, including condensation precipitation. The increase in precipitation reduces the cost of field irrigation in summertime. The proposed economic equivalent is cost of 1 cubic meter of water per ecological zone.

Guided by the recommendations [26], the economic value of ecosystem service $\left(O_{\mathrm{OC}}\right)$ is given by:

$$
O_{\mathrm{oc}}=\sum_{j=1}^{\mathrm{m}} X_{\mathrm{av}} \beta_{j} S_{j} C_{\mathrm{w}}
$$

where $O_{\mathrm{oc}}$ is the economic value of ecosystem service of humidity growth, rubles; $X_{\mathrm{av}}$ is the precipitation in summer, $\mathrm{mm}$ or cubic meter per ha; $\beta_{j}$ is the coefficient of precipitation gain in the territory covered by a j-th plantation type, $\% ; S_{j}$ is the area occupied by the $j$-plantation type, ha; $C_{\mathrm{w}}$ is the cost of 1 cubic meter of water in a given economic zone, rubles per cubic meter.

$$
\beta=W G P / X_{\mathrm{av}},
$$

where $W$ is the woodiness, \%; GP is the gain in precipitation per increment percent of woodiness, $\mathrm{mm}$ or cubic meter per ha.

We think formula (8) should be adjusted by introducing a coefficient that takes into account retention of liquid precipitation by vegetation, which is proved by numerous observations over forest canopy. According to [18], in different physical and geological conditions, on average $12-13 \%$ of liquid precipitation is retained by forest as against the nonforest area. The held precipitation is $19-25 \%$ for coniferous and deciduous forests, $27-31 \%$ for spruce forest, $26-32 \%$ for fir forest, etc. Hence, it is recommended to introduce the retention coefficient of precipitation of the $j$-th plantation type $\left(\mathrm{Y}_{\mathrm{j}}\right)$ in formula (8).

The soil protection service is also inherent to forest, which means protection of soil from water and wind erosion. Researchers state that up to 10-15 tons of soil is washed off from 1 ha of land with medium slope, while soil contains $P, N$, $\mathrm{Co}$, humus-layer, etc. As a result, crop yields fall. Forests arrest land-loss and, accordingly, loss of chemical elements and humus-layer. Generalization of guidelines on the economic assessment of this ecosystem service shows numerous and equally valid methodical tools for:

- the reduction in cost of removal of sediments washed into water bodies based on the cost of extraction of 1 ton sediment by dredger;

- the increase in yield of agricultural land adjacent to the estimated forest area and, accordingly, by the income gain;

- the evaluation of crop shortage provided that 1 ha of forest ecosystem prevents erosion on an area of $0.5 \mathrm{ha}$, and the crop shortage is $10-30 \%$ on little lost land, $30-50 \%$ medium lost land and $50-80 \%$ on greatly lost land [27]);

- evaluation of chemical elements lost in land-loss based on the prices of mineral fertilizers;

- percentage of total economic value of supporting ecosystem services (0.53 as per [28]).

We assume to be the most reliable to undertake economic assessment by the cost of washed-out chemical elements based on the prices of mineral fertilizers at the average reference land-loss of 10-12 tons per 1 ha in the absence of forest fertilizers. It is possible to take into account the anticipated crop yield increase on agricultural land adjacent to the forest:

\section{Table 2. Discount rates}

\begin{tabular}{|c|c|c|c|c|c|}
\hline $\begin{array}{c}\text { Discount } \\
\text { period }\end{array}$ & $\begin{array}{c}\text { Discount } \\
\text { rate }\end{array}$ & $\begin{array}{c}\text { Discount } \\
\text { period }\end{array}$ & $\begin{array}{c}\text { Discount } \\
\text { rate }\end{array}$ & $\begin{array}{c}\text { Discount } \\
\text { period }\end{array}$ & $\begin{array}{c}\text { Discount } \\
\text { rate }\end{array}$ \\
\hline 5 & 0.17 & 17 & 0.08 & 70 & 0.03 \\
\hline 6 & 0.15 & & 0.07 & 75 & 0.02 \\
\hline 7 & 0.14 & 25 & 0.06 & 80 & 0.02 \\
\hline 8 & 0.12 & 30 & 0.05 & 85 & 0.02 \\
\hline 9 & 0.12 & 35 & 0.05 & 90 & 0.02 \\
\hline 10 & 0.11 & 40 & 0.04 & 95 & 0.02 \\
\hline 11 & 0.1 & 45 & 0.04 & 100 & 0.02 \\
\hline 12 & 0.1 & 50 & 0.03 & 120 & 0.02 \\
\hline 13 & 0.09 & 55 & 0.03 & 150 & 0.01 \\
\hline 14 & 0.09 & 60 & 0.03 & 200 & 0.01 \\
\hline 15 & 0.08 & 65 & 0.03 & & \\
\hline
\end{tabular}

$$
O_{\mathrm{sp}}=\mathrm{p} \cdot 0.5 \sum_{y}^{p} R_{\text {crop }} S_{\text {crop }} P_{\text {crop }}
$$

where $O_{\mathrm{sp}}$ is the economic value of soil protection ecosystem service, rubles; $p$ is the probability of erosion prevention, decimal quantity; 0.5 is erosion prevention per 1 ha of forest ecosystem, ha per ha; $S_{\text {crop }}$ is the area occupied by a $j$-th crop, ha; $R_{\text {crop }}$ is the gain in agricultural crops, kg per ha; $P_{\text {crop }}$ is the price of $1 \mathrm{~kg}$ of agricultural crop, rubles per $\mathrm{kg}$; $y$ is crop $(y=1 \ldots p)$.

All previous formulas offer the economic evaluation of ecosystem services per year. However, the effectiveness of the ecosystem potential of forests is materialized pursuant to the spatial and temporal dynamics of forest ecosystems, which requires taking into account the time factor. In some cases, the discounting procedure is neglected, which seems to increase the economic values of ecosystem services. The total economic value is determined in this case by summing up the annual economic values for the period equal to the lifetime of an object (or an estimated period). V. P. Krasovsky wrote about the inexpediency of discounting in the long-term period, he considered that this procedure should be applied only in the short term [29]. T. Kislova [30], as well as the authors [31], point at the risk of obtaining far from reality results with discounting for periods of $50-100$ years.

Recommendations often involve discounting at a reduced discount rate up to $2-3 \%$ or less. I. V. Voronin and V. P. Smorodin [32] propose to use the discount rate in the range of $0.05-$ 0.15. The Forestry Commission in England recommends the discount rate on the level of 5\%; and P. Pierce [33] reduces the rate to $1-2 \%$. The reduced discount rate of 0.02 in the economic evaluation of forests was also recommended by the working group of the USSR Academy of Sciences Commission. The validity of the application of the minimum discount rate is supported, in particular, by E. V. Ryumina [34]. The same approach to setting of a discount rate was once promoted by K. G. Hoffman, who proposed the introduction of a discount standard of $0.04-0.05$ for evaluating agricultural land and 0.02-0.03 for evaluating forest land [35]. V. A. Gavrilov suggests using a sliding discount rate, which decreases with extension of the discounting period [36].

Later on, it was proposed to rate discounting depending on the length of a discounting period (Table 2) [14, 15].

It follows from the analysis that forest assessments most often use the discount rate of $1-3 \%$, which implies a unified approach to evaluation of forest benefits. Thus, the discounting application research is continued, and specific difficulties 
are connected with the economic assessment of ecosystem services. In the meanwhile, without officially approved guidelines, researchers use the capitalization procedure with a capitalization rate from 0.01 to 0.03 .

\section{Conclusion}

1. The mineral sector, which is the basis of civilization, is at the same time a threat to natural biota. The anthropogenic impact of mining on the environment leads to the formation of ecological zones with different rate of change in the biocenosis in mine-adjacent areas. The transformation rate difference is explained by a decrease in the anthropogenic impact with an increasing distance from the impact source.

2. As experience shows, the main object of the anthropogenic impact is forest ecosystems as mineral deposits are located more often among forests. The resultant damage hurts flows of environmental goods and services supplied by them in the implementation of the resource and ecosystem functions.

3. To assess the economic damage that reflects the damage to forest ecosystems, it is proposed to use the resource approach that assumes comparability between the degree of ecosystem disturbance and the loss of its economic value.

4. The reliability of the economic damage determination rests upon the comprehensive economic assessment of natural resources and services of ecosystems subjected to the impacts. The greatest difficulties are associated with the economic assessment of ecosystem services due to the insufficient development of the relevant procedures and tools.

5. The generalization and analysis of methodical approaches to the economic assessment of ecosystem services in maintenance of atmospheric air composition has made it possible to substantiate a consistent implementation procedure meant for increasingly detailed calculations. It is recommended to perform preliminary economic studies using averaged values of the initial information.

6. The economic assessment of the ecosystem service on the humidity buildup through the retention of liquid precipitation by the plant canopy has been clarified. We systematized the methodical approaches to assessing the ecosystem service of soil protection from erosion, which makes it possible to choose the most appropriate assessment method for the specific conditions.

7. The studies confirm the absence of generally accepted decisions on implementation of the discounting procedure in economic assessment. In most cases, researchers use the reduced discount rates or even perform simple summation of annual economic values over a period equal to the lifetime of an object (or an estimated period).

\section{Acknowledgments}

The research was supported by the Ministry of Science and Higher Education in accordance with the state assignment for Ural State Mining University No. 0833-2020-0008, "Development and environmental and economic substantiation of the technology for reclamation of land disturbed by the mining and metallurgical complex based on reclamation materials and fertilizers of a new type". We obtained the scientific results with the staff of Center for the collective use by using the equipment of the Center for the collective use of scientific equipment of the Federal Scientific Center of biological systems and agricultural technologies of RAS (No Ross RU.0001.21 PF59, the Unified Russian Register of Centers for Collective Use - http://www.ckp-rf.ru/ckp/77384)
References

1. Ryumina E. V., Anikina A. M. Assessment of environmental pollution damage in the Russian regions. Ekonomika nedropolzovaniya. 2006. Vol. 5. pp. 89-95.

2. Lebedev Yu. V. Theoretical foundations of ecologically sustainable development of the territory: patriotic vision. Yekaterinburg: UGGU, 2015. $156 \mathrm{p}$.

3. Brown L. R. Eco-economy : building an economy for the Earth. London, New York : W. W. Norton \& Company, 2001. 327 p.

4. Lukyanova N. V., Myaskov A. V. The influence of the mining industry on specially protected natural territories. GIAB. 2007. Vol. 6. pp. 323-330.

5. Ignatieva M. N., Litvinova A. A., Loginov V. G. Methodical tools for the economic assessment of the environmental impact of mining. Ekaterinburg : IE UrO RAN, 2010. 168 p.

6. Shadrina E. G., Volpert Ya. L., Danilov V. A., Shadrin D. Ya. Bioindication of the impact of the mining industry on the terrestrial ecosystems of the North. Novosibirsk : Nauka, 2003. 107 p.

7. Recognition of the nature economy. Synthesis of approaches, conclusions and recommendations of TEEV : Project "The Economics of Ecosystems and Biodiversity". Moscow, 2010. 49 p.

8. Fomenko G. A., Fomenko M. A., Loshadkin K. A., Mikhailova A. V. Monetary valuation of natural resources, society and ecosystem services in managing biodiversity conservation: experience of regional works. Yaroslavl : NPP Kadastr, 2012. 65 p.

9. Pakhomov V. P., Ignatieva M. N., Belyaev V. N. et al. Methodical materials on the relationship of the indigenous peoples of the North with economic entities. Yekaterinburg : IE UrO RAN, 2000. 63 p.

10. Ignateva M. N., Loginov V. G., Litvinova A. A., Morozova L. M., Ektova S. N. The economic assessment of harm to the arctic ecosystems at the development of oil and gas resources. Economy of Region. 2014. Vol. 1. pp. 102-111. DOI: 10.17059/2014-1-9.

11. Kosolapov O. V., Ignatyeva M. N., Litvinova A. A. Economic damage caused by consequences of the environmental impact of mining complex. Economy of Region. 2013. Vol. 1. pp. 158-166. DOI: 10.17059/2013-1-15

12. Tatarkin A. I. (Ed). The development of consistency in the development of the natural potential of the northern poorly known areas. Yekaterinburg : IE UrO RAN, 2015. 317 p.

13. Balashenko V. V., Ignatieva M. N., Loginov V. G. Natural resources potential of northern regions: Consistent features of comprehensive assessment. Economy of the Region. 2015. Vol. 4. pp. 84-94. DOI: 10.17059/2015-4-7

14. Lebedev Yu. V. Assessment of forest ecosystems in environmental economics. Yekaterinburg : UrO RAN, 2011. 574 p.

15. Krupinin N. Ya., Lebedeva T. A. Information support for assessment work on forest lands of the Middle Urals (subsoil use area). Yekaterinburg : UGGU, 2015. $116 \mathrm{p}$.

16. Yurak V. V. The guidelines for the economic assessment of regulatory and social ecosystem services. Yekaterinburg : UrO RAN, 2018. 55 p.

17. Voronov M. P., Chasovskykh V. P. A Method of economic evaluation of environment forming forest functions. Eko-potentsial. 2013. No. 1-2. pp. 13-23.

18. Protopopov V. V. The Supporting Role of a Dark Coniferous Forest. Novosibirsk: Nauka, 1975. 328 p.

19. Zamolodchikov D. G, Utkin A. I., Korovin G. N. Determination of carbon reserves by conversion-volume coefficients depending on the age of plantations. Lesovedenie. 1998. Vol. 3. pp. 84-93. 
20. Utkin A. I., Ermolova L. S. Zamolodchikov D. G. Conversion coefficients for determining the leaf area of plantations of the main forest-forming species of Russia. Lesovedenie. 1997. Vol. 3. pp. 74-78.

21. Tsvetkov V. F. Ecological functions of forests of the Arkhangelsk Region. Some issues of forest science and forestry in the European North of Russia. Arkhangelsk : Arkhangelsk State University, 2015. 158 p.

22. Zubov M. A. Ecological and Economic Assessment of Forest Resources of the Khanty-Mansi Autonomous Area. Problemy regionalnoi ekonomiki. 2015. Vol. 1. pp. 81-85.

23. Moreva L. S. Economic evaluation of forest lands under anthropogenic impact. Ecological and economic features of the use and reproduction of forest resources: collected papers. Krasnoyarsk, 1983. pp. 81-86.

24. Petkau V. V. Ecological and economic problems of the development of forestry in Russia: thesis of inauguration of Dissertation ... of Candidate of Economic Sciences., Moscow, 2001. 22 p.

25. Kuznetsova L. P. The role of the relief and forests in the distribution of precipitation amount on the plain. Trudy GGO. 1957. Iss. 72. pp. 76-91.

26. Lebedev Yu. V., Neklyudov I. A. Assessment of the water conservation and water regulatory role of forests. Guidelines. Yekaterinburg : UGLU, 2012. 35 p.
27. Tishkov A. A. (Ed.) Economy of biodiversity conservation. Moscow, 2002. 246 p.

28. Lebedev Yu. V. Ecological and economic assessment of the supporting potential of landscapes in the Krasnoyarsk Territory. Geografiya i prirodnye resursy. 2013. No. 2: 166-173.

29. Krasovsky V. P. The integral effect and the time factor. Voprosy ekonomiki. 1974. No. 8. pp. 3-13.

30. Kislova T. 1986. On the consideration of the time factor in industries associated with the use of long-term natural processes. Ekonomicheskie nauki. 1986. No. 4. pp. 53-57.

31. Afanasyeva I. N., Biryukov P. A., Kuzmina M. V. About the time factor in the forecast for the development agricultural production. Lesa Rossii i khozyaistvo v nikh. 2015. No. 4. pp. 53-58.

32. Voronin I. V., Smorodin V. P. On forest valuation. Izvestiya vys shikh uchebnykh zavedeniy. Lesnoi zhurnal. 1970. No. 5. pp. 123-128.

33. Pearce P. Introduction to the forest economy. UBC Press, 2002.

34. Ryumina E. V. Economic analysis of damage from environmental lawlessness. Moscow, 2009. 331 p.

35. Hoffman K. G. Economic assessment of natural resources in a socialist economy. Moscow : Nauka, 1977. 224 p.

36. Gavrilov V. A. Accounting for the time factor in the economic assessment of forest lands. Lesovodstvo $i$ agrolesomelioratsiya. 1978 . Iss. 52. pp. 32-35. EM

V. S. LITVINENKO ${ }^{1}$, Rector, Doctor of Engineering Sciences, Professor

P. S. TSVETKOV ${ }^{1}$, Assistant, Candidate of Economic Sciences, pscvetkov@yandex.ru

K.V. MOLODTSOV ${ }^{1}$, Leading Researcher

${ }^{1}$ Saint-Petersburg Mining University, Saint-Petersburg, Russia

\section{THE SOCIAL AND MARKET MECHANISM OF SUSTAINABLE DEVELOPMENT OF PUBLIC COMPANIES IN THE MINERAL RESOURCE SECTOR}

\section{Introduction}

The need for the global economy to transition to a sustainable development path is no longer in doubt. There is also no question that industrial enterprises should contribute to this process. Today, the most frequently discussed matter is the extent to which private investment is required for this transition, whether it is necessary to differentiate requirements depending on the industry, what measures should be applied to enterprises that are unable to implement waste-free process chains etc. In fact, to this day no feasible path to achieving sustainability, which would suit multiple industries and help to preserve them has been proposed. Both from the point of view of preserving the ability of future generations to meet their needs, and from the point of view of economic stability of companies in the long term.

It is relatively easy to talk about sustainable development (SD) when it comes to industries which have always been "green", such as renewable energy,
In the present time, the world's attention is focused on issues regarding the transition of mining enterprises to a path of sustainable development, which is determined by their role in the functioning of all sectors of the economy. The numerous theories, concepts and methods associated with this transition invariably face difficulties at the stage of practical implementation which as yet have not been resolved. The main disadvantage of the existing approaches is their orientation towards forming a policy of state regulators, which contradicts the very essence of market relations. This paper proposes a different approach to ensuring the sustainability of public mining companies, based on the creation of incentives for the development of corporate social responsibility policy. The main element of the proposed mechanism is stock exchanges with enough influence and resources to promote and popularize companies striving to make their production more environmentally friendly and to maximize their social effects. The viability of the proposed approach is confirmed by the growing "green" investment market, which at present is somewhat limited in the industry but has enormous potential for further expansion, including with support from mining companies.

Key words: sustainable development, social and market mechanism, mining industry, public companies, corporate social responsibility, sustainable investments, social license, stock exchanges

DOI: 10.17580/em.2020.01.07 